\title{
Introduction of the international impressive figures in the fields of dermatology, dermatopathology, cosmetology and skin biology- Part I
}

\author{
Nooshin Bagherani ${ }^{1 *}$ and Bruce R Smoller ${ }^{2 *}$
}

${ }^{1}$ Dermatologist at Dr. Nooshin Bagheran's Office, Taha Physicians' Building, P.O. Box: 6414715878, Khoramshahr, Khuzestan Province, Iran

${ }^{2}$ Professor and Chair, Department of Pathology, Professor, Department of Dermatology, University of Rochester, School of Medicine and Dentistry, USA

In our role as Guest Co-Editors of this series, we are pleased to offer an additional informational piece as part of the overall educational program. Our field of dermatology and the related fields of dermatopathology, cutaneous biology, dermatologic surgery and cosmetology have grown enormously and made enormous strides in the diagnosis and treatment of skin diseases in recent decades. These advances occurred as a result of great individuals, often working in concert with other great individuals, dedicated teams and supportive institutions and governments. While some of the "giants" in our fields are well know to all, many of these brilliant scientists and innovators are less known, especially to our younger colleagues at the beginning phases of their careers. With the hope of providing sources of inspiration and insights into how we got where we are as a global network of dermatologic health care providers, we will endeavor to present a series of biographies designed to highlight the professional accomplishments of our international role models. We will present this series, initially with some of our own personal sources of inspiration and motivation, but we heartily welcome recommendations for additional role models to feature in each of the subsequent editions. Often, we learn by example and sharing the works of the "greats" may serve to help the next generation to aspire to even greater accomplishments. If you enjoy reading about this group of "stars", please do not hesitate to contact us with your own recommendations and allow us to make this a worldwide show of recognition. We hope that you are as excited by these great leaders as we were when we put this series together.

To notify, the biographies have been arranged alphabetically.

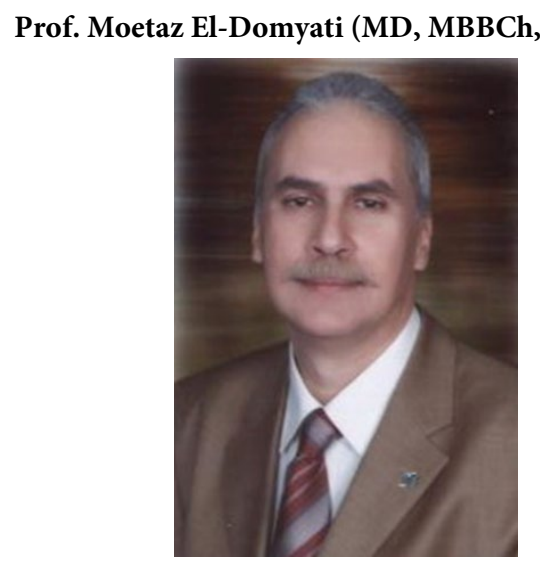

Prof. Moetaz El-Domyati was born on the $31^{\text {st }}$ of March, 1957 in
Cairo. He got his Medical degree (MBBCh) in 1980, Master degree in Dermatology and Venereology (MSc) in 1984, Diploma of Surgery (DS) in 1986 and his Doctoral degree (MD) in 1989 from Ain Shams University. He was appointed as a full Professor at Al-Minya University in 1999 and as the Head of the Dermatology and Venereology department from 2005 to 2011 . He was designated as a member of the Egyptian Universities Promotion Committee for promotion to Associate Professor and Professor Titles from 2008 up till now. He is also a member of Egyptian Fellowship Board of Dermatology, Ministry of Health, from 2009 to present date.

Dr. El-Domyati currently serves as a Professor of Dermatology, STD's and Andrology, Al-Minya University, Egypt. He published over 150 international and regional publications and shared as an invited speaker in many international dermatologic, cosmetic and aesthetic congresses worldwide. He acted as a faculty member and chairperson in many international conferences all over the globe, and secretary general and president of several dermatology international conferences at Al-Minya, Egypt.

Prof. El-Domyati has been awarded the Perry Robbins award, international society of dermatologic surgery; $1987,18^{\text {th }}$ world congress of dermatology award, New York, USA; 1992, Egyptian medical syndicate award; 2007, Al-Minya University Appreciation award; 2012

Correspondence to: Nooshin Bagherani, Dermatologist at Dr. Nooshin Bagheran's Office, Taha Physicians' Building, P.O.Box: 6414715878, Khoramshahr, Khuzestan Province, Iran; E-mail: nooshinbagherani@yahoo.com

Bruce R Smoller, Professor and Chair, Department of Pathology, Professor, Department of Dermatology, University of Rochester, School of Medicine and Dentistry, USA, E-mail: bsmoller@me.com

Special Issue: Dermatology History in Different Countries

Nooshin Bagherani M.D.

Dermatologist at Dr. Nooshin Bagheran's office, Taha Physicians' building, P.O.Box: 6414715878, Khoramshahr, Khuzestan Province, Iran; Email: nooshinbagherani@yahoo.com

Bruce R. Smoller, M. D.

Chair, Department of Pathology and Laboratory Medicine Professor, Department of Pathology and Laboratory Medicine Professor, Department of Dermatology

University of Rochester School of Medicine and Dentistry, USA

E-mail: smollerbrucer@uams.edu

Published: December 20, 2015 
and Al-Minya University international publication award from 2012 to 2015. His Biography was included several times in Who's Who in the World, USA, and the International Biographical Centre (IBC), Cambridge, UK.

Prof. El-Domyati was among the first researchers who quantitatively and objectively evaluated the effect of different lasers, radiofrequency devices, dermabrasion, chemical peeling and microneedling on skin aging after facial rejuvenation, as well as expression of P53 protein and different apoptotic markers in different skin conditions and after the use of most facial rejuvenation techniques and modalities.

\section{Prof. Andy Goren (MD, PhD)}

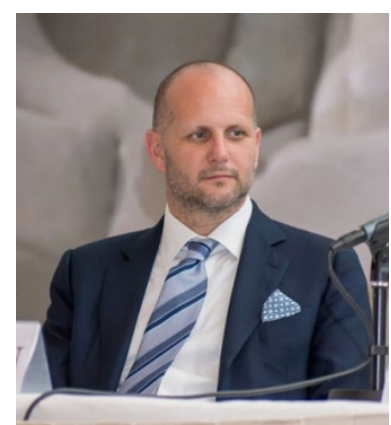

Prof. Andy Goren has over 15 years of experience in research, development and launch of breakthrough medical technologies.

Among the list of many firsts in dermatology, Professor Goren was the first to develop a clinical genetic test for predicting androgenetic alopecia, the first to discover epigenetic markers predicting antiandrogen therapy response in female androgenetic alopecia, the first to develop a clinical acne vulgaris antibiotic response test based on P. Acnes bacterial genomics, and the first to develop a rapid test for predicting minoxidil response in androgenetic alopecia.

Dr. Goren recently completed the development, commercialization, and listing with the U.S. FDA of a breakthrough topical drug for vitiligo, psoriasis and atopic dermatitis. His latest research involves the development of dermatology therapies based on genetically modified organisms.

Prof. Goren currently serves as a Professor of Dermatology at the University of Rome "G.Marconi", Italy. He is an honorary as well as ordinary member of several dermatology societies world-wide, a scientific reviewer for Dermatologic Therapy, a lecturer in several international dermatology societies, and held numerous appearances and interviews on mainstream TV, radio, and prestigious newspapers. His accomplishments include numerous patents and publications related to his inventions and discoveries. Prior to his work in Dermatology, Professor Goren developed a medical device to correct gait disorders in peripheral neuropathy patients using sensory substitution, as well as invent the first wire-free electric charger for mobile devices.

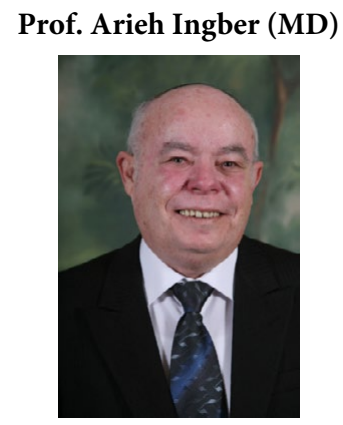

Prof. Arieh Ingber is Associate Professor of Dermatology, Fillip Frost Professor in Clinical Dermatology at the Department of Dermatology, Hadassah University Hospital, Faculty of Medicine, Hebrew University, Jerusalem, Israel. He was the Chairman of the Department of Dermatology At Hadassah University Hospital (19952014).

Prof. Ingber earned his medical degree at the Sackler School of Medicine, Tel Aviv University in 1983, and studied dermatopathology in Department of Dermatology, University of Cologn, Germany in 1981-1982. He passed a research fellowship in contact dermatitis at Gentofe Hospital, University of Copenhagen, Denmark in 1989. He received his training in dermatology at the Department of Dermatology, Rabin Hospital Campus Beilinson, Petach-Tikva, Tel Aviv University.

Prof. Ingber is member of the Israel Society of Dermatology and Venereology, the Israel Society of Pediatric Dermatology, the Israel Society of dermatological Surgery and the Israel Society of Contact Dermatitis. He was the President of the Israel Society of Contact Dermatitis (1990-1996) and the Israel Society of Dermatology and Venereology (2011-2014). He is also member of the American and European Academies of Dermatology, American and European Societies of Contact Dermatitis, Honorary member of German Society of Dermatology, Corresponding member of Finnish Society of Dermatology, Member of Israel National Council for Public Health. He is one of the founders and member of Board of Directors, Euro-Asia Association of Dermatology.

Prof. Ingber published more than 200 papers on dermatology, chapters in textbooks of dermatology and the textbook of "Obstetric Dermatology".

His main interests include contact dermatitis, obstetric dermatology, psoriasis, bullous diseases and history of dermatology.

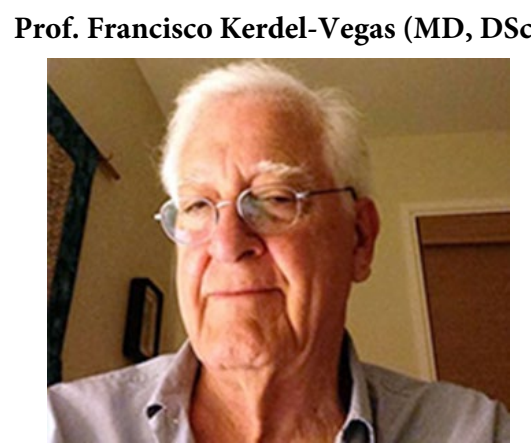

Prof. Francisco Kerdel-Vegasis an internationally known dermatologist. He graduated in Medicine at the Central University of Venezuela, and in dermatology at the Massachussetts General Hospital, at Harvard Medical School in Boston, at the New York Skin and Cancer Unit. He was awarded a master's of science in dermatology and syphilology from New York University, and the honorary degree of DSc from the California College of Podiatric Medicine, and from Cranfield University in England.

In 1954, Dr. Kerdel-Vegas was assigned as assistant professor of dermatology at the Central University of Venezuela. In 1961, he achieved Professorship in Dermatology. He was a member of Trinity College, Cambridge, England and served the Experimental Pathology Department of this university as visiting scientist. In 1967 he was elected Life Member of the National Academy of Medicine of Venezuela.In 1984-1989, he was President of the "International Society 
of Dermatology".He served his country as Ambassador to Great Britain (1987-1992) and UNESCO and France (1992-1999).

ln 1968, Dr. Kerdel-Vegas was the first pro-vice-chancellor of the newly-organized Universidad Simon Bolivar, and a member of the National Research Council of Venezuela. ln 1970, he was a member of the executive committee of the Metropolitan University, Caracas. Since 1972, he has been Fellow of the American College of Physicians, in Philadelphia.

Prof. Kerdel-Vegas is Honorary Member of the National Academies if Medicine of Brazil, Colombia, Chile and Paraguay and Correspondent Member of the Royal Academy of Doctors (Cataluña, Spain). He has been elected member of many dermatological societies (LatinAmerica, USA, Great Britain, France, Germany, Austria).

Prof. Kerdel-Vegas and his colleagues described two new dermatologic entities: disseminated leishamaniasis and erythema dyschromicum perstans and discovered the active principle (selenocystathionine) for the depilatory effects of the ingestion of the seeds of the Coco de Mono (Lecythis ollaria) tree.

Prof. Kerdel-Vegas has been decorated with the highest orders of Venezuela, and is a Commander of the British Empire and Member of the Legion of Honor (France). And up to now, he achieved numerous national and international awards for his work and research.

He has five textbooks and over 150 articles in the fields of tropical and dermatological diseases.

Dr. Koushik Lahiri (MBBS, DVD, International Fellow of AAD, FIAD, FAADV, MRCPS (Glasgow), FRCP (Edin)

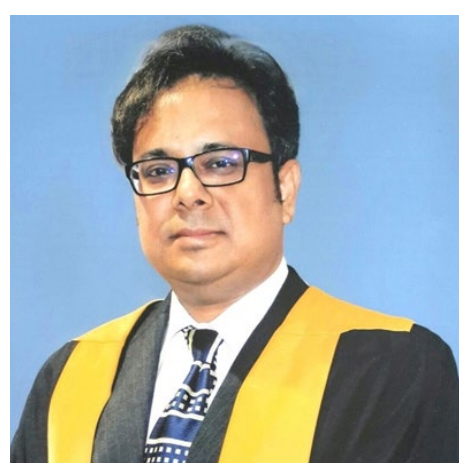

Dr. Koushik Lahiri is a member of board of Directors of the "International Society of Dermatology" (2013-2017), immediate past President of "Association of Cutaneous Surgeons of India" (2013-2015), and Editor-in Chief of the "Indian Journal of Dermatology" (20122017). In the years of 2006 to 2008, he was Honorary General Secretary of the "Indian Association of Dermatologists, Venereologists, and Leprologists" (IADVL). During his tenure in IADVL, this association could re-establish its link and become member of the "International League of Dermatological Societies" (ILDS) after a gap of one decade. $\mathrm{He}$ is founder council member of Asian Skin Foundation and Asian Society for Pigment Cell Research (ASPCR). He also is foundation Fellow and Board member, Asian Academy of Dermatology and Venerology.

Dr. Lahiri initiated the biggest social imitative under IADVL against misuse of topical corticosteroid in India. He, as President of the "Association of Cutaneous Surgeons of India", initiated the countrywide Community Dermatosurgery project in 2014.
Dr. Lahiri has more than 100 published articles in various National and international journals to his credit. In 2013, he edited a textbook on "Pigmentary Disorders", a multi-authored compendium, a never before project on the topic from India.

In 2013, Dr. Lahiri achieved membership of Royal College of Physicians and Surgeons(MRCPS), Glasgow. In 2014, fellowship of Royal College of Physicians (FRCP), Edinburg was conferred upon him. In the 41st National Conference of Indian Association of Dermatologists, Venereologists and Leprologists, he delivered DR. B M AMBADY Oration at DERMACON 2013. In 2015 he was honored for outstanding leadership, with special recognition from the Rutgers State University of New Jersy and New Jersey Medical School Chapter of Sigma Xi, the Scientific Research Society.

\section{Prof. Torello Lotti , MD, MD (Hon)}

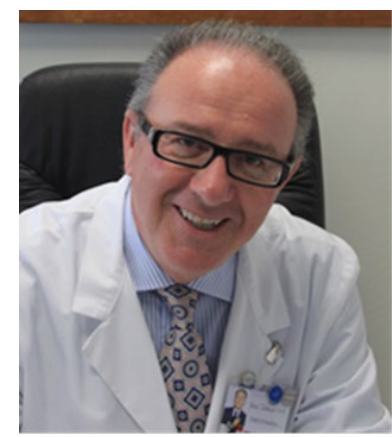

Dr. Torello Lotti Lotti is Full Professor of the Dermatology and Venereology at University of Studies Guglielmo Marconi, Rome, Italy. He is President of the World Health Academy, Dermatology since 2013.

He is Director of the Centro Studi per la Ricerca Multidisciplinare Rigenerativa (CSRMR), of the University of Rome "G.Marconi", Rome, Italy, since 2015.

Honorary Professor of Dermatology - China Medical University Shenyang (2011), Lecturer, New York Academy of Sciences "Howard Fox Memorial Lecture” (14 March 2012 - New York, NY - USA), Chair, Executive Scientific Committee Vitiligo Research Foundation, New York, NY USA.

He has been Full Professor of the Dermatology and Venereology Division at University of Florence School of Medicine, Florence, Italy, from 2006 to 2010. Visiting Professor in six International Universities worldwide, Key Note Lecturer in several international dermatology Societies.

Prof. Lotti has been President of the Italian Society of Dermatology and Venereology (SIDeMaST, 2009-2010), President of the International Society of Dermatology ( ISD, 2009-2010), President of the European Society for Cosmetic and Aesthetic Dermatology (2003-2004), Editor in Chief of the Journal of the European Academy of Dermatology and Venereology (1992-2002), Editor "Therapeutic Hotline"- Dermatologic Therapy (2007-), Scientific reviewer of ten sectorial journals- British JD, JIDermatology, JAAD, Dermatologic Therapy. Author or co-author of over 1500 scientific publications, 
including scientific papers, book chapters and books. Out of these publications over 400 are peer-reviewed papers, with a cumulative Impact Factor of circa 1000.

\section{Prof. Keyvan Nouri, MD}

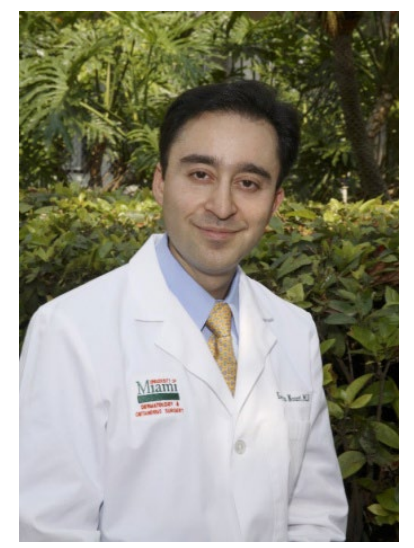

Dr. Keyvan Nouri is professor of dermatology, ophthalmology, and otolaryngology. He is Vice Chairman of the University of Miami Medical Group, Chief of Dermatology Services at Sylvester Comprehensive Cancer Center/University of Miami Hospital and Clinics, Director of Mohs, Dermatologic \& Laser Surgery, and Director of Surgical Training for the University Of Miami Department Of Dermatology.

$\mathrm{He}$ is the editor-in-chief of "Lasers in Medical Science" and editor of the "Journal Investigative Dermatology'sCells to Surgery Quiz" and section editor for various other journals including "Dermatologic Surgery" and "International Journal of Dermatology". He has authored 7 textbooks, over 180 peer-reviewed scientific articles, 116 book chapters, and many other manuscripts. He has completed many clinical research trials including: lasers for treatment of scars, lasers for treatment of skin cancers, attempting to define the peak absorption of basal cell carcinomas, treatment of acute wounds with artificial skins and lights, among others.

Besides his leadership roles within UM, he also has various leadership roles for the Florida Society of Dermatologic Surgeons (past president and current program co-chairman), American Society of Dermatologic Surgery (past program co-chairman of mastery of lasers course), American College of Mohs Surgery, the American Society of Lasers in Medicine and Surgery, and the International Society of Dermatology (current vice-president and previous co-chairman for continental meetings).

Some of his honors include Alpha Omega Alpha Honor Medical Society, American Dermatological Association, Phi Beta Kappa Honor Society, Castle Connolly, U.S. News America's Top Doctors, Best Doctors in America, and Surgeon of the year for the Florida Society of Dermatologic Surgery among others.

\section{Prof. Lidia Rudnicka (MD, PhD)}

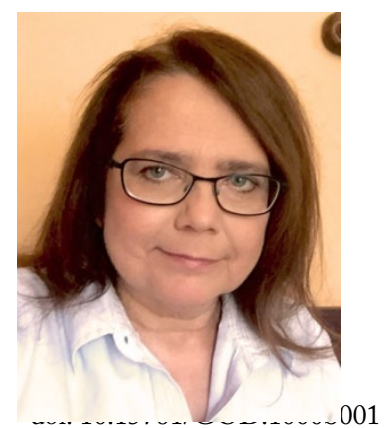

Dr. Lidia Rudnicka is professor and chairman at the Department of Dermatology at Warsaw Medical University in Poland. She has gained valuable experience at multiple institutions such as Food and Drug Administration (USA), University of Liège (Belgium) and Thomas Jefferson University in Philadelphia (USA). Lidia Rudnicka has authored or co-authored over 200 articles and book chapters.

Her main scientific achievement is development of trichoscopy (hair and scalp dermoscopy). She coined the term "trichoscopy" in 2008. She directed a team, which has worked out standard procedures in trichoscopy, established normal values, and classification of trichoscopy finding. She is the editor of the Atlas of Trichoscopy, published in English and in Portuguese, which has become a basic manual for dermatologists, who perform trichoscopy. Her department is being visited by multiple dermatologists and residents who seek to learn trichoscopy.

Her other fields of interest and scientific achievements include research in melanoma, systemic sclerosis, psoriasis and lichen planus.

Dr. Lidia Rudnicka is vice-chairman and chairman-elect of the Posters Exhibit Task Force of the American Academy of Dermatology. She is the founder and editor-in-chief of the Journal of Dermatological Case Reports, associate editor of JEADV and member of the editorial board of multiple other scientific journals. Lidia Rudnicka was speaker at multiple dermatology meetings, including World Congresses of Dermatology in New York, Sydney, Paris, Buenos Aires, Seoul and Vancouver. She has served as faculty at multiple meetings of the American Academy of Dermatology and European Academy of Dermatology and Venereology.

\section{Prof. Khalifa E Sharquie ( MD, PhD)}

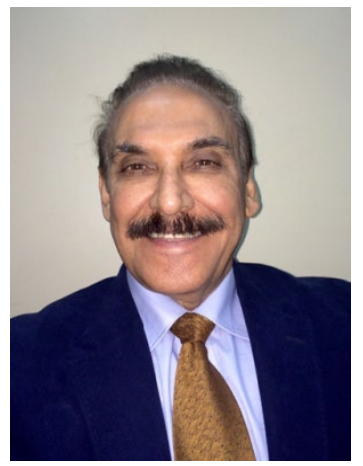

Dr Khalifa ESharquie is Professor and member of Scientific Council of Iraqi and Arabic Board of Dermatology and Venereology. $\mathrm{He}$ is consultant and professor of dermatology, Department of Dermatology, College of Medicine, University of Baghdad, Baghdad Teaching Hospital.

Sharquie graduated from college of Medicine, University of Baghdad in 1974.He was trained in dermatology and internal medicine in Baghdad, England and Scotland. He achieved his PhD degree of Dermatology in 1981 from University of Sheffield, England. He was the Head of Dermatology Department, university of Baghdad since 19892005 and chairman of Iraqi board of dermatology from 1994-2013. He introduced skin surgery, dermatopathology and cosmetology into skin training and specialty.

Dr.Sharquie is the founder of Diploma, Iraqi Board in Dermatology \& Venereology and The Iraqi Arabic in Dermatology.He had 10 Patents 
in different skin problems and invented many new skin entities and numerous skin therapeutics.

Sharquie published more than 260 publications and articles. He shared in publishing chapters in 7 dermatological books. He supervised the following theses: 85 Diploma, 13 Msc,84 Iraqi Boards and 7 PhDS. Additionally he is interested in literature and poetry; he has 7 poetry books.

Dr. Sharquie is a reviewer and a member of editorial board of many medical journals. He received Diploma Honorary Membership of Sigma Xi, The Scientific Research Society, USA (Feb.12.2014). He also received the World Health Academy Honorary Membership Award in 2014. His main interests are skin therapeutics, dermatopathology,skin electron microscopy, leishmaniasis, pigmentary disorders, Behcets disease, oral medicine, skin tumors, hair problems, skin and laser surgery,cosmetology and other clinical researches.

\section{Prof. Bruce R. Smoller (MD)}

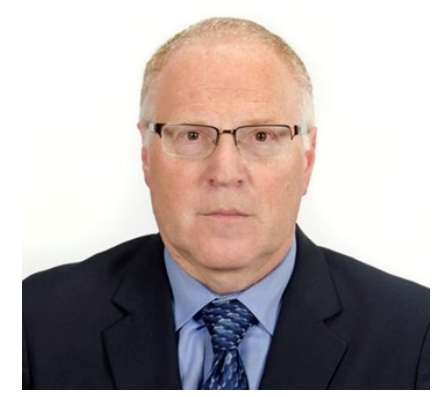

Dr. Smoller began his career in pathology as a resident in anatomic and clinical pathology at Harvard's Beth Israel Hospital. From there, he did a dermatopathology fellowship at Cornell Medical School/ New York Hospital under the tutelage of Dr. Scott McNutt. He remained on faculty at Cornell for several years before relocating to Stanford University in 1990 to assume the position as Director of Dermatopathology and rose through the ranks to become a Professor of Pathology and Dermatology. In 1997, he relocated to the University of Arkansas where he became Chair of the Department of Pathology, in addition to his role as the Director of Dermatopathology. He remained there until 2011 when he was appointed to the position of Executive Vice President of the United States and Canadian Academy of Pathology. He spent nearly three years in that position before accepting the position as Professor and Chair, Department of Pathology and Laboratory Services and Professor of Dermatology at the University of Rochester School of Medicine and Dentistry, where he has been since July 2014.

Dr. Smoller has published more than 245 original articles, 39 book chapters and 13 textbooks of dermatopathology. He has served as the Editor-in-Chief of the Journal of Cutaneous Pathology and as the President of the American Society of Dermatopathology. He has been invited as a guest speaker in 22 countries around the world. He is proudest of the Nickel Award he received from the American Society of Dermatopathology in recognition of lifetime excellence in teaching.

\section{Prof. Michael D. Tharp (M.D)}

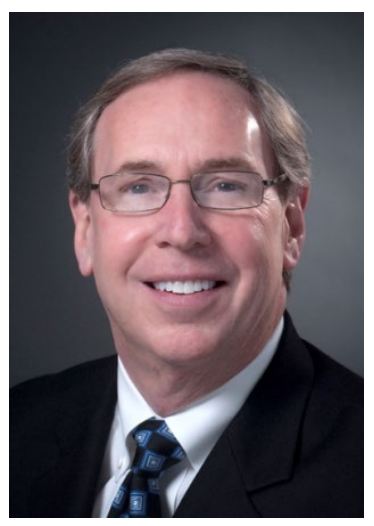

Dr. Michael D. Tharp is Clark W. Finnerud, M.D, Professor and Chair of the Department of Dermatology at Rush University Medical Center. He graduated cum laude from both Ohio Wesleyan University and from Ohio State University Medical School in 1971 and 1974, respectively. He completed three years of internal medicine training at Parkland Memorial Hospital in Dallas, Texas, before finishing a dermatology residency and fellowship at Duke University Medical Center in Durham, North Carolina in 1980. Dr. Tharp is board certified in both specialties.

He served on the faculty as an Assistant and Associate Professor in the Departments of Dermatology and Internal Medicine at Southwestern Medical School in Dallas, Texas for seven years prior to becoming Professor and Vice-Chairman of the Department of Dermatology at the University of Pittsburgh School of Medicine in Pittsburgh in 1987. Dr. Tharp moved to Rush University Medical Center in Chicago in 1995 where he is presently the Clark W. Finnerud M.D., Professor and Chair in the Department of Dermatology.

Dr. Tharp has written over 180 papers, book chapters, books and abstracts. He is the Chief Editor of Dermatologic Therapy, President of the Dermatology Foundation, and past President of the Association of Professors of Dermatology (APD) and Chicago Dermatological Society. He also is a past Vice President of the Society of Investigative Dermatology, a member of the Board of Trustees and Executive Committee of the Dermatology Foundation, and a past Board member of the American Academy of Dermatology. Dr. Tharp has served on numerous committees for the AAD, APD and ADA. He currently chairs the Research Agenda committee and is co-Chair of the Pruritus Work group for the AAD.

His primary research interest is in mast cells as they relate to urticaria, pruritus, atopic dermatitis, and mastocytosis. His clinical research interests include itch, psoriasis, atopic dermatitis, cutaneous $\mathrm{T}$ cell lymphoma, and immune bullous diseases.

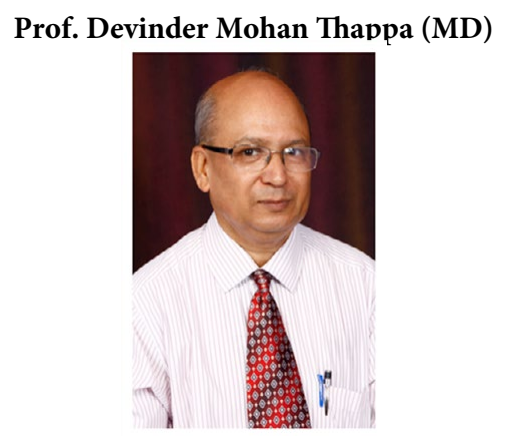


Dr. Devinder Mohan Thappa, Professor, of Dermatology and Sexually Transmitted Diseases since 2002 (earlier as head from 19962013) and Professor-in-charge and Head, Faculty Publications since 2013, Jawaharlal Institute of Postgraduate Medical Education and Research (JIPMER), Puducherry, India.

Dr. Thappa obtained his postgraduate degree from PGIMER, Chandigarh, India in 1989. He had 3- year experience of teaching undergraduates and postgraduates at Lady Hardinge Medical College, New Delhi (1989-1992). Currently, he is Founder Editor-in-Chief of two medical science journals namely, International Journal of Advanced Medical and Health Research, and Pigment International. Involved in curriculum designing and its implementation for undergraduates and postgraduates at JIPMER, he has to his credit over 550 scientific publications in International/National specialty journals, and authorship of three books. He was the Editor-in-Chief of Indian
Journal of Pediatric Dermatology, and Indian Journal of Dermatology, Venereology and Leprology.

Dr. Thappa has been awarded with prestigious "Ambady, Sardari Lal, and AK Dutta Memorial Orations" by Indian Association of Dermatologists, Venereologists, and Leprologists, and Dr. Sardari Lal Memorial Oration Award for best paper in Indian Journal of Sexually Transmitted Diseases, along with WHO Fellowship on STD and AIDS under University of Washington, Seattle, USA. He is a Fellow of National Academy of Medical Sciences, and International Medical Science Academy, New Delhi. He was declared 'International Man of the Millennium’ by International Biographic Centre, London in 1999 and subsequently awarded with '2000 Outstanding Intellectuals of the $20^{\text {th }}$ Century Award' in March 2000 and ' 2000 Outstanding Intellectuals of the $21^{\text {st }}$ Century Award' in 2001.

Copyright: ( 2015 Bagherani N. This is an open-access article distributed under the terms of the Creative Commons Attribution License, which permits unrestricted use, distribution, and reproduction in any medium, provided the original author and source are credited. 